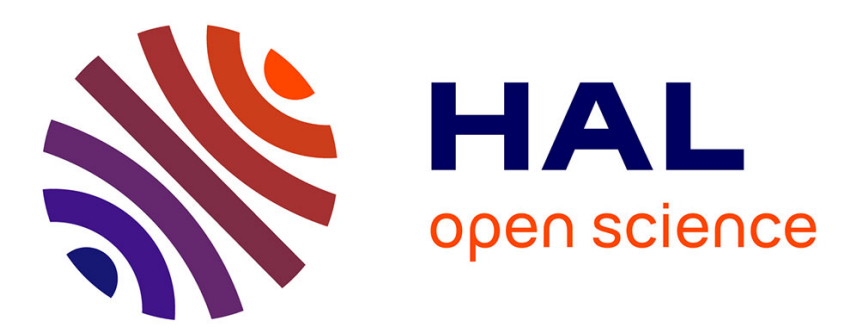

\title{
Reduced graphene oxide film based highly responsive infrared detector
}

\author{
Mustaque A. Khan, Karuna K. Nanda, Saluru B. Krupanidhi
}

\section{To cite this version:}

Mustaque A. Khan, Karuna K. Nanda, Saluru B. Krupanidhi. Reduced graphene oxide film based highly responsive infrared detector. Materials Research Express, 2017, 4 (8), pp.085603. 10.1088/2053-1591/aa8042 . hal-02471039

\section{HAL Id: hal-02471039 \\ https://hal.science/hal-02471039}

Submitted on 7 Feb 2020

HAL is a multi-disciplinary open access archive for the deposit and dissemination of scientific research documents, whether they are published or not. The documents may come from teaching and research institutions in France or abroad, or from public or private research centers.
L'archive ouverte pluridisciplinaire HAL, est destinée au dépôt et à la diffusion de documents scientifiques de niveau recherche, publiés ou non, émanant des établissements d'enseignement et de recherche français ou étrangers, des laboratoires publics ou privés. 


\section{Reduced graphene oxide film based highly responsive infrared detector}

This content has been downloaded from IOPscience. Please scroll down to see the full text.

Download details:

IP Address: 14.139.128.16

This content was downloaded on 20/07/2017 at 09:58

Manuscript version: Accepted Manuscript

Khan et al

To cite this article before publication: Khan et al, 2017, Mater. Res. Express, at press: https://doi.org/10.1088/2053-1591/aa8042

This Accepted Manuscript is: @ 2017 IOP Publishing Ltd

During the embargo period (the 12 month period from the publication of the Version of Record of this article), the Accepted Manuscript is fully protected by copyright and cannot be reused or reposted elsewhere.

As the Version of Record of this article is going to be / has been published on a subscription basis, this Accepted Manuscript is available for reuse under a CC BY-NC-ND 3.0 licence after the 12 month embargo period.

After the embargo period, everyone is permitted to copy and redistribute this article for non-commercial purposes only, provided that they adhere to all the terms of the licence https://creativecommons.org/licences/by-nc-nd/3.0

Although reasonable endeavours have been taken to obtain all necessary permissions from third parties to include their copyrighted content within this article, their full citation and copyright line may not be present in this Accepted Manuscript version. Before using any content from this article, please refer to the Version of Record on IOPscience once published for full citation and copyright details, as permission will likely be required. All third party content is fully copyright protected, unless specifically stated otherwise in the figure caption in the Version of Record.

When available, you can view the Version of Record for this article at: http://iopscience.iop.org/article/10.1088/2053-1591/aa8042 


\title{
Reduced Graphene Oxide Film Based Highly
}

\section{Responsive Infrared Detector}

\author{
Mustaque A. Khan ${ }^{\dagger}$, Karuna K. Nanda ${ }^{\dagger}$ and Saluru B. Krupanidhi*广 \\ ${ }^{\dagger}$ Materials Research Centre, Indian Institute of Science, Bangalore 560012, India
}

E-mail: sbk@mrc.iisc.ernet.in, sbkenator@gmail.com

\begin{abstract}
Due to the unique optical properties, graphene can effectively be used for the detection of infrared light. In this regard, reduced graphene oxide (RGO) has drawn considerable attention in scientific society because of simplicity of preparation and tunable properties. Here, we report the synthesis of RGO by solvothermal reduction of graphene oxide (GO) in ethanol and the detection of infrared light (1064 and $1550 \mathrm{~nm})$ with metal - RGO - metal configuration. We have observed that photocurrent, responsivity as well as the external quantum efficiency increase with $\mathrm{C} / \mathrm{O}$ ratio. The responsivity value in near-infrared region can be as high as 1.34 A. $\mathrm{W}^{-1}$ and the external quantum efficiency is more than $100 \%$. Response times of these devices are in the order of few seconds. Overall, the responsivity of our device is found to be better than many of the already reported values where graphene or reduced graphene oxide is the only active material. The high value of quantum efficiency is due to strong light absorption and the presence of mid-gap state in RGOs.
\end{abstract}

KEYWORDS: reduced graphene oxide, infrared detector, mid-gap state, temperature sensor 


\section{INTRODUCTION}

Now-a-days, infrared detectors are being used in many applications such as rail safety, gas leak detection, flame detection, night flying, night surveillance, night vision goggles and also space operations.[1] Graphene is a zero band gap material so it absorbs a broad spectrum of light. This property has made graphene a highly potential material for infrared detector. Unfortunately, a single layer graphene absorbs only $\sim 2.3 \%$ of incident white light,[2] and photo-generated electrons and holes in graphene recombine within few picoseconds.[3-5] Lower absorption and faster carrier recombination lead to low photo-response.[6-8] In order to use graphene as an effective photodetector, absorption as well as life time of photo-excited electrons and holes should be increased. Built-in electric field near metal-carbon nanotube junction can separate photogenerated electron and holes, preventing quick recombination.[9] But this kind of effects are limited at the junctions. Introduction of defects in graphene sheets leads to creation of band gap and also limits the recombination of charge carriers.[6, 7, 10] Though plasmonic nanostructures, micro-cavities have been used to enhance the absorption efficiency of graphene,[11-14] responsivity still remains in few tens of $\mathrm{mA} . \mathrm{W}^{-1}$. The light absorption efficiency can also be increased by simply increasing the number of layers in graphene.[15] Therefore, few layers graphene with considerable amount of defects on the sheets is a potential material for highly responsive infrared photo-detector.[16, 17] Few layers structure and ease preparation makes reduced graphene oxide (RGO) a very important candidate of the graphene family. Properties of RGO can be tuned by tuning the amount of reduction [18-22] and also it can be reduced by many different reducing agents.[23-26] We have prepared RGO without using any extremely harmful chemicals like hydrazine and also the method of preparation is simple. We have used ethanol as reducing agent.[27] It effectively reduces graphene oxide. We also 


\section{EXPERIMENTAL SECTION}

report the detection of infrared light. The devices consisting of "metal - RGO - metal" configuration show high responsivity even at very low bias. The responsivity in NIR region can be as high as $1.34 \mathrm{~A} . \mathrm{W}^{-1}$ and the external quantum efficiency $>100 \%$ has been achieved. Response times of these devices are in the order of few seconds. To our knowledge, the responsivity is much better than most of devices based on graphene or RGO as the only active material.

2.1 Materials and Method. Graphite flakes were purchased from Sigma Aldrich. Potassium permanganate $\left(\mathrm{KMnO}_{4}\right)$ and sulfuric acid $\left(\mathrm{H}_{2} \mathrm{SO}_{4}\right)$ were purchased from Fisher Scientific. Sodium nitrate and hydrochloric acid were purchased from SDFCL. Ethanol was purchased from local supplier. All the chemicals were at least more than $99 \%$ pure and used without further purification.

Graphitic oxide (GO) is prepared according to Hummers method. Details of the method are reported elsewhere.[28] Reduction of GO is achieved by solvothermal method with ethanol as solvent. First, $80 \mathrm{mg}$ of $\mathrm{GO}$ is added to $40 \mathrm{ml}$ of ethanol. Then these mixtures are sonicated for $200 \mathrm{~min}$. in a $30 \mathrm{kHz}$ TELSONIC ULTRASONICS bath sonicator. After sonication, GO dispersion is transferred into a $50 \mathrm{ml}$ teflon lined autoclave and kept in a muffle furnace at $180^{\circ} \mathrm{C}$ for $3,6,12,24$ and $36 \mathrm{~h}$. After solvothermal reduction, the furnace is allowed to cool naturally. After that the product mixtures are centrifuged at $5000 \mathrm{rpm}$ and washed with ethanol. Then the products are dried in vacuum overnight. The RGOs are named as RGO1, RGO2, RGO3, RGO4, and RGO5 for 3, 6, 12, 24, and 36h of reduction respectively. 
2.2 Characterizations. X-ray diffraction (XRD) studies have been carried out using RigakuSmartLab X-ray diffractometer with $\mathrm{Cu} \mathrm{K \alpha}$ as X- ray source. Raman spectra have been acquired using LabRAM HR system with $532 \mathrm{~nm}$ excitation source. Absorption and infrared (IR) spectra have been recorded using PerkinElmer UV/VIS/NIR Lambda 750 spectrometer and Bruker FTIR instrument, respectively. X-ray photoelectron spectroscopy (XPS) measurements have been done using KRATOS ANALYTICAL's AXIS Ultra photoelectron spectrometer with $\mathrm{Al} \mathrm{K \alpha}$ as X-ray source. Scanning electron microscopy (SEM) images are taken with ZEISS's GEMINI ULTRA 55 FE-SEM, while transmission electron microscopy (TEM) images are taken with FEI Tecnai F30 S-TWIN TEM.

2.3 Device Fabrication and Opto-electrical Measurement. Silver electrodes with $200 \mathrm{~nm}$ thickness and a gap of $95 \mu \mathrm{m}$ are deposited on cleaned quartz substrates by thermal evaporation (Figure S1). To fabricate the devices, $4.8 \mathrm{mg}$ of $\mathrm{RGO}$ is dispersed in $150 \mu \mathrm{L}$ toluene by sonication and drop-casted in between the electrodes with a micro pipette. The devices are dried at $\sim 40^{\circ} \mathrm{C}$ on a hotplate for $\sim 45 \mathrm{~min}$. and cooled to the room temperature. A CNI's MDL-III 1550 $\mathrm{nm}$ laser (with an optical coupler of $\sim 2 \mathrm{~mm}$ radius) and MIL-III $1064 \mathrm{~nm}$ (with a beam radius 2.5 $\mathrm{mm}$ ) have been used as the IR source. Optical chopper SR540 has been used for chopping measurements. Tektronix Keithley 2400 source measure instrument is used for electrical studies.

\section{RESULTS AND DISCUSSION}

SEM images [Figure S2(a) and (b)] reveal some amount of agglomeration in RGO. TEM images [Figure S2(c) and (d)] reveal the layered nature of RGO. Inter-layer spacing is $\sim 3.5 \AA$. SAED pattern [Figure S2(d) inset] reveals hexagonal symmetry with inner most diffraction spots corresponding to (1100) planes and diffraction spots next to that are from (2110) planes. (1100) 
planes correspond to a d-spacing of $\sim 0.19 \mathrm{~nm}$ and (2110) planes correspond to a d-spacing of $0.11 \mathrm{~nm}$. XRD pattern (Figure S3) of GO shows a peak at around $11.86^{\circ} 2 \theta$. Oxygen functionalities incorporation in between the (002) planes lead to larger interplanar distances.[29] After reduction, diffraction peak restores around graphitic peak $\left(26.51^{\circ} 2 \theta\right)$ at $25.46^{\circ} 2 \theta$. Very broad nature of the peaks is due to few layers structure and presence of defects in RGO. Absorption spectrum of GO and RGOs have been taken in N-Methyl-2-pyrrolidone (NMP). As the reduction increases, the absorption increases in visible and infrared spectrum (Figure 1 a). Infrared spectra of $\mathrm{GO}$ and $\mathrm{RGO}$ (Figure S4) also indicate restoration of aromaticity after reduction. Alkane $\mathrm{C}-\mathrm{H}$ stretching and $\mathrm{C}-\mathrm{H}$ rocking absorption intensity also decreases. On the other hand $\mathrm{C}-\mathrm{C}$ aromatic stretching absorption and $\mathrm{C}-\mathrm{H}$ in plane bending absorption increases. EDS and XPS survey spectra of GO and RGO (Figure S5) show vivid difference of carbon and oxygen contain before and after reduction of graphitic oxide. Figure $1 \mathrm{~b}$ shows the XPS C1s spectrum of GO which can be deconvoluted to four peaks. These peaks are arising from C$\mathrm{C} / \mathrm{C}=\mathrm{C}(\sim 284.5 \mathrm{eV}), \mathrm{C}-\mathrm{O}(\sim 286.5 \mathrm{eV}), \mathrm{C}=\mathrm{O}(\sim 288.3 \mathrm{eV})$ and $\mathrm{CO}(\mathrm{OH})(\sim 290.2 \mathrm{eV}) .[30]$ The very nature of $\mathrm{C} 1 \mathrm{~s}$ peak of $\mathrm{GO}$ indicates oxygen incorporation on the layers of graphite flakes and the $\mathrm{C} / \mathrm{O}$ ratio is $~ 1.96$. XPS C1s spectrum (Figure 1c) show that oxygen functionalities are mostly removed during reduction process. The $\mathrm{C} / \mathrm{O}$ ratio for different $\mathrm{RGOs}$ has been evaluated from the XPS spectra and produced in table 1. Raman spectra of GO, RGO3 (Figure 1d) show four major peaks. The strong peak at $\sim 1590 \mathrm{~cm}^{-1}$ corresponds to $\mathrm{G}$ peak.[31] Raman peaks at 1345 and $2695 \mathrm{~cm}^{-1}$ are called as D peak and 2D (or G') peak and the peak around $2935 \mathrm{~cm}^{-1}$ is known as $\mathrm{D}+\mathrm{G}$ peak.[31, 32] For perfectly crystalline graphene $\mathrm{D}$ - band remains absent because the corresponding $\mathrm{A}_{1 \mathrm{~g}}$ mode does change the overall polarizability.[33] It requires defect or disorder in the crystal to get activated.[33, 34] D peak only appears when size of the graphene sheets 
decreases or defects gets incorporated on graphene sheets and can be used to quantify amount of defects in graphene. Though, the ratio of $I_{D} / I_{G}$ is the measure of defects in graphene, [31, 33-35] the ratio obtained for GO and RGO is inconclusive as the value is very much position-dependent. Non-uniform size, presence of heteroatom in GO and RGO leads to position dependent $\mathrm{I}_{\mathrm{D}} / \mathrm{I}_{\mathrm{G}}$ value.

(a)

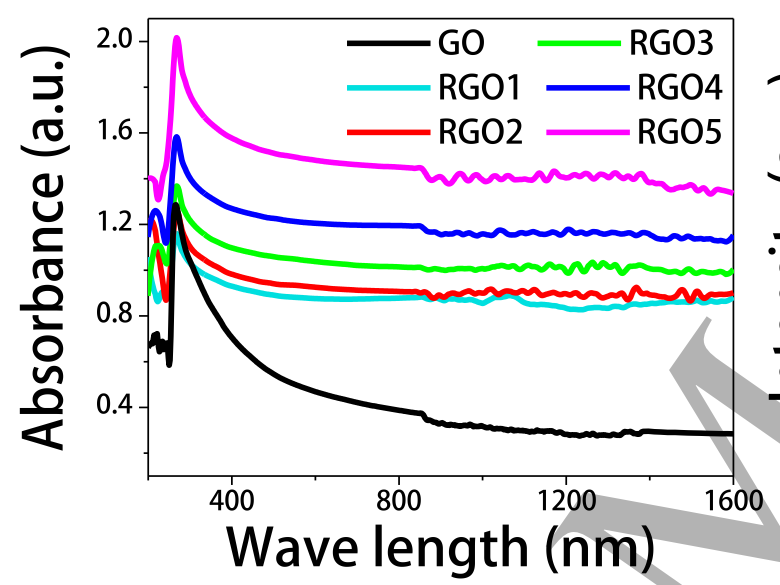

(c)

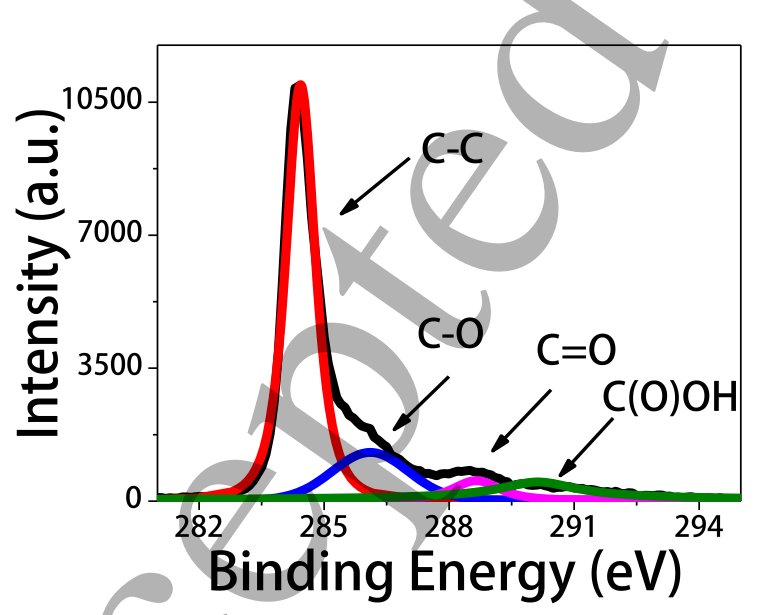

(b)

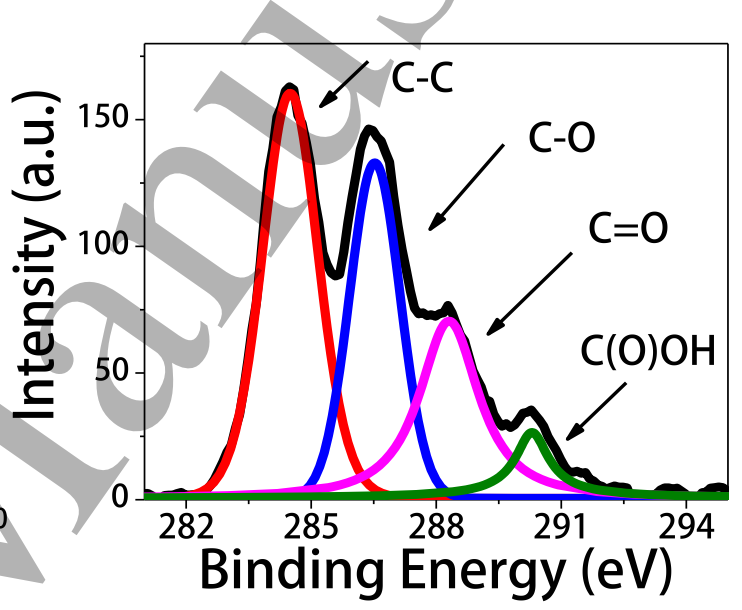

(d)

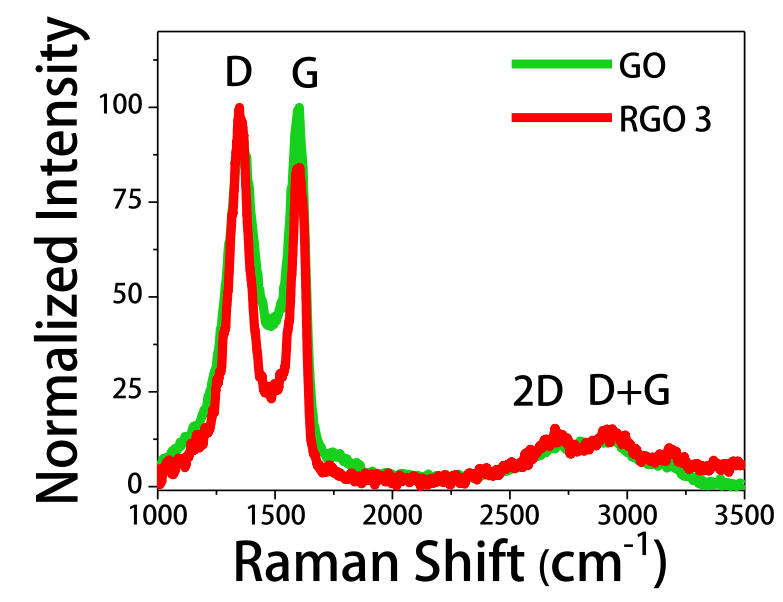

Figure 1. (a) Absorption spectra of RGO samples, (b and c) XPS C1s spectra of GO and RGO3 respectively, (d) Raman spectra of GO and RGO. 
Table 1. Atomic percentage of carbon and oxygen in RGO as obtained from XPS analysis.

\begin{tabular}{|l|l|l|l|}
\hline Sample & C $\%$ & O & C/O \\
\hline GO & 66.27 & 33.73 & 1.96 \\
\hline RGO 1 & 85.73 & 14.27 & 6.00 \\
\hline RGO 2 & 86.29 & 13.71 & 6.29 \\
\hline RGO 3 & 86.97 & 13.03 & 6.67 \\
\hline RGO 4 & 87.19 & 12.81 & 6.80 \\
\hline RGO 5 & 87.41 & 12.59 & 6.94 \\
\hline
\end{tabular}

Photocurrent measurements of the devices are carried out with 1550 and $1064 \mathrm{~nm}$ laser irradiation. Figure 2a shows the temporal response curves for RGO3 with $1550 \mathrm{~nm}$ excitation with a bias of $0.3 \mathrm{~V}$. As soon as IR radiation falls on the device, photocurrent quickly increases and reaches its saturation level and the saturated photocurrent increases with increasing IR radiation intensity. Increase in intensity of IR/ radiation generates higher number of excited electrons and holes that leads to higher photocurrent. To determine the relation between photocurrent $\left(\boldsymbol{I}_{\boldsymbol{P C}}=\right.$ current after illumination - dark current $)$ and intensity of radiation $\left(\boldsymbol{I}_{\boldsymbol{L}}\right)$ we have plotted $\boldsymbol{I}_{\boldsymbol{P C}}$ vs. $\boldsymbol{I}_{\boldsymbol{L}}$ at a constant bias of $0.3 \mathrm{~V}$ and fitted with the equation,

$I_{P C}=\alpha * I_{L}^{\beta}$,

where $\boldsymbol{\alpha}$ and $\boldsymbol{\beta}$ are constants. $\boldsymbol{\beta}$ is $1.14,1.27,1.45,1.28$ and 1.28 for RGO1, RGO2, RGO3, RGO4, and RGO5, respectively with $1550 \mathrm{~nm}$ irradiation (Figure 2b). Temporal responses of RGO3 at different intensities of $1064 \mathrm{~nm}$ excitation (at a constant voltage of $0.3 \mathrm{~V}$ ) are shown in figure $2(\mathrm{c}) . \boldsymbol{\beta}$ is found to be 1.64, 1.58, 1.57, 1.64 and 1.55 for RGO1, RGO2, RGO3, RGO4 and RGO5, respectively [Figure 2(d)]. The non-unity of $\boldsymbol{\beta}$ values is indicative of complex processes 
of electron-hole generation, trapping of electrons and recombination.[6, 36, 37] In this context, it is worthy to note that photocurrent is linear with bias voltage as shown in figure S6.

(a)

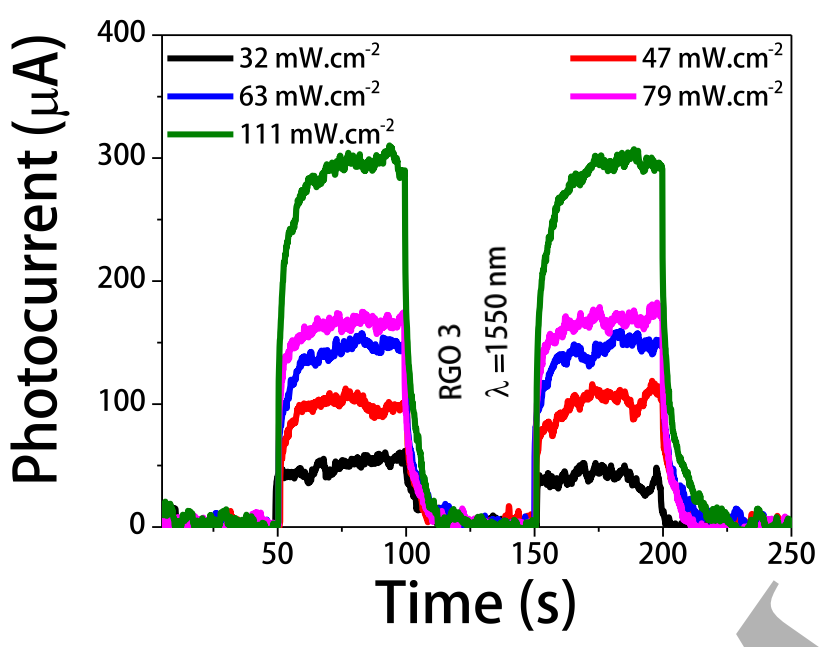

(c) (b)

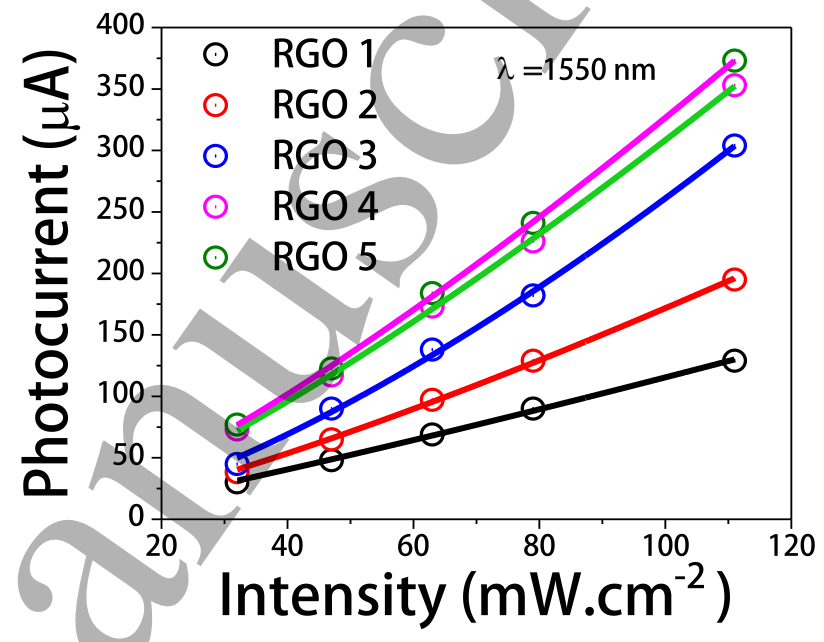

(d)
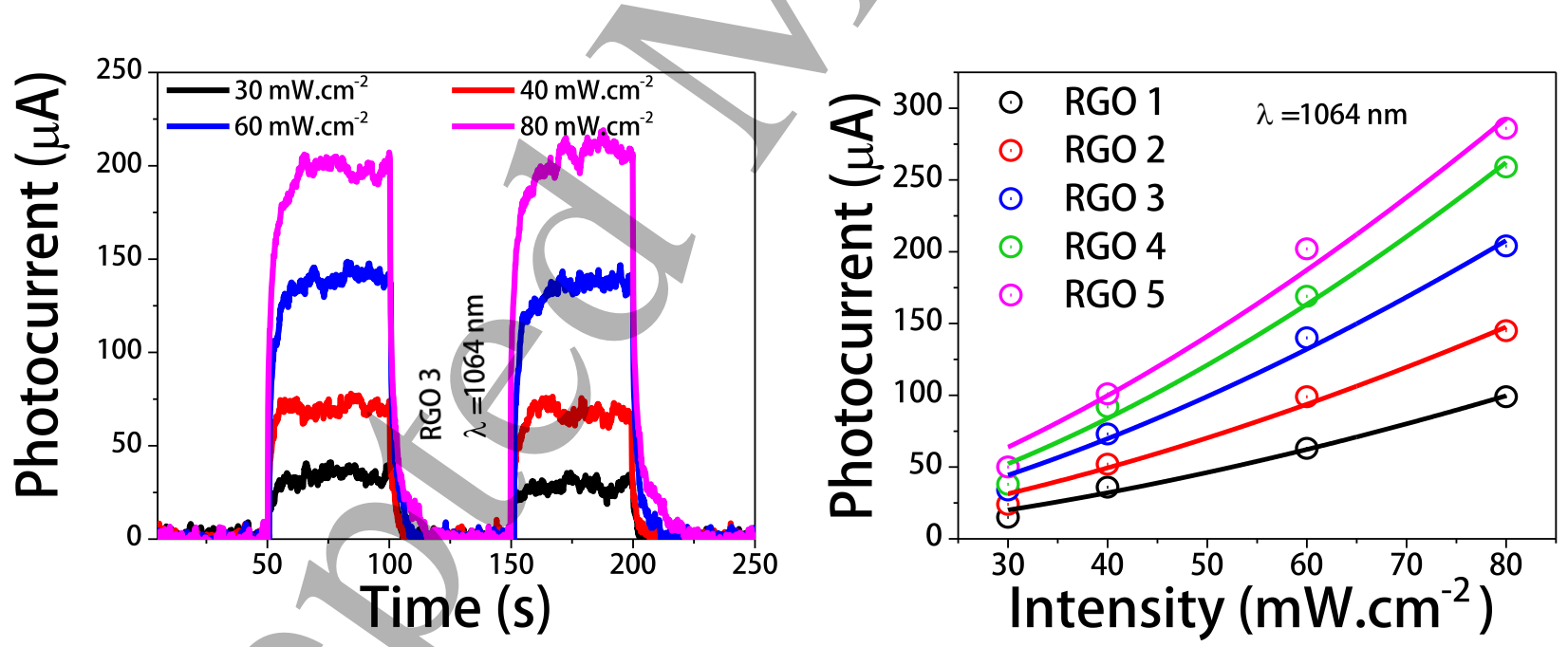

Figure 2. Photoresponse of RGO3 to (a) $1550 \mathrm{~nm}$ and (c) 1064 radiation with different radiation intensity at constant bias of $0.3 \mathrm{~V}$. (b and d) variation of photocurrent with intensity.

Bolometric temperature rise of RGO can also lead to generation of photocurrent.[38, 39] In order to shed /ight on this, we studied the effect of temperature on electrical properties of the devices 
and measured the temperature rise by irradiation (Figure S7 and Table S1). No appreciable rise in temperature $(<0.1$ degree) could be detected (with a resistance temperature detector, resolution of $0.1 \mathrm{~K})$ for $\sim 50 \mathrm{~s}$ exposure of infrared radiation $\left(\sim 80 \mathrm{~mW} \cdot \mathrm{cm}^{-2}\right)$. We have also carried out photocurrent studies using a chopper [Figure S8]. It is well known that bolometric temperature rise $\left(\Delta \mathbf{T}_{\mathbf{B}}\right)$ depends on chopper frequency and the bolometric effect is dominant at lower frequency. This indicates that bolometric effect can be avoided at higher frequency. However, we observed no change in photocurrent with the variation of chopper frequency [Figure S8 (b) and (c)]. The initial decrease in photocurrent during chopping is due to reduction of laser exposure time to half of its initial value. These two measurements suggest photocurrent is due photovoltaic effect and not bolometric effect.

Figure 3(a) and (b) display the temporal photoresponse of RGOs with 1550 and $1064 \mathrm{~nm}$ radiation of $80 \mathrm{~mW} . \mathrm{cm}^{-2}$ at $0.5 \mathrm{~V}$. Irrespective of the excitation wavelength, it is interesting to note that photocurrent increases with $\mathrm{C} / \mathrm{O}$ ratio as shown in Figure 3(c). As the $\mathrm{C} / \mathrm{O}$ ratio increases, the band gap of RGO decreases.[21, 40, 41] As the band gap decreases, the absorption cross section increases that causes the generation of more electron-hole pair and produces higher photocurrent.

Responsivity $(\boldsymbol{R})$ of a photodetector indicates the efficiency of photocurrent generation per unit incident radiation per unit area. Responsivity of a photodetector is calculated as,

$\boldsymbol{R}=\boldsymbol{I}_{\boldsymbol{P C}} /\left(\boldsymbol{I}_{\boldsymbol{L}} * \boldsymbol{A}\right)$,

where $\boldsymbol{I}_{\boldsymbol{P C}}$ is the photocurrent, $\boldsymbol{I}_{\boldsymbol{L}}$ is the light intensity and $\boldsymbol{A}$ is the effective area.[7, 42, 43] The external quantum efficiency $(\boldsymbol{E Q E})$ is the ratio of the number charge carrier collected by the 
device to the number of photons irradiated on the effective area $(\boldsymbol{A})$ of the device and can be estimated using the relation,

$E Q E=h c R / e \lambda$,

where $\boldsymbol{h}$ is the Plank's constant, $\boldsymbol{c}$ is the velocity of light, $\boldsymbol{e}$ is the charge of an electron and $\boldsymbol{\lambda}$ is the wavelength of incident radiation.[7, 44]

(a)
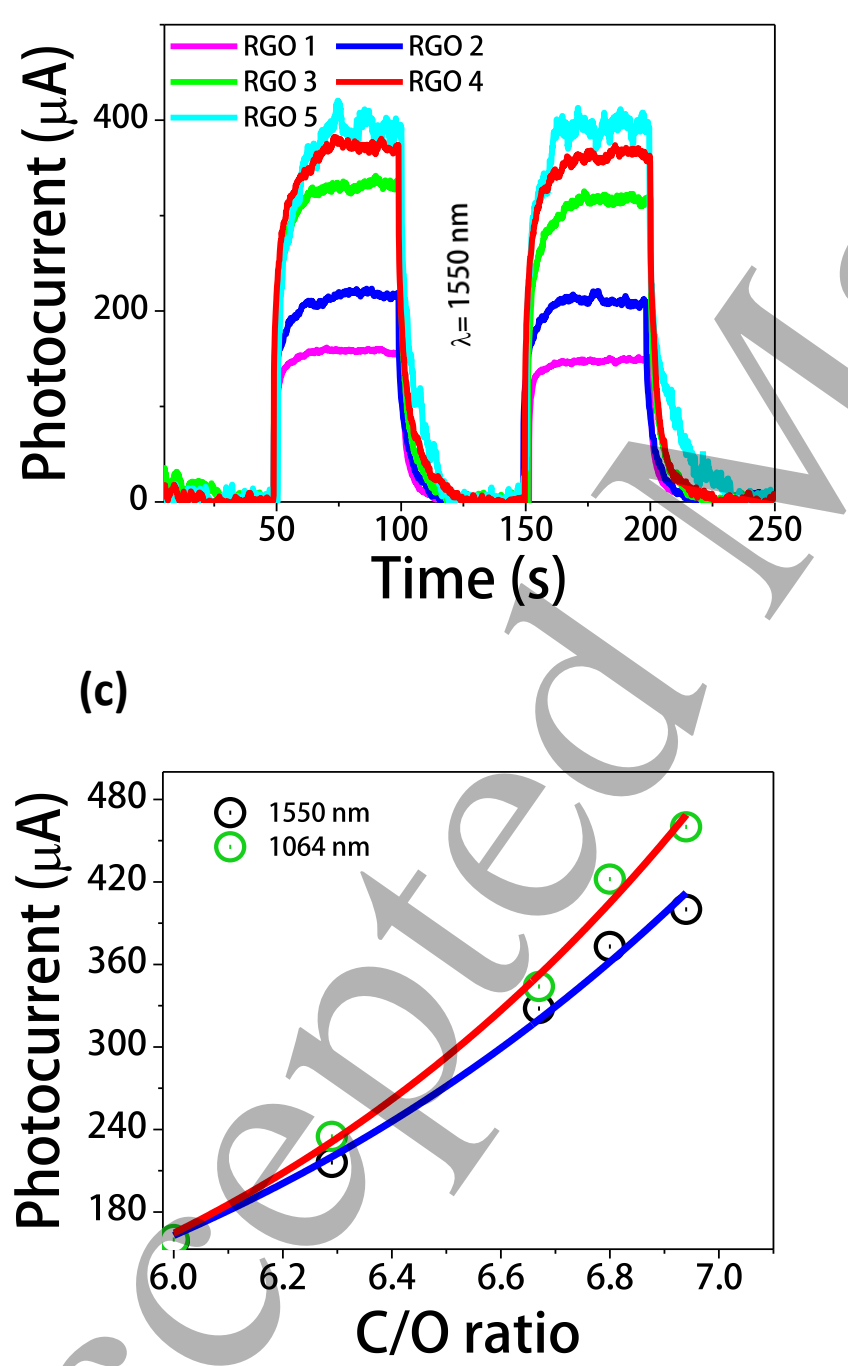

(b)

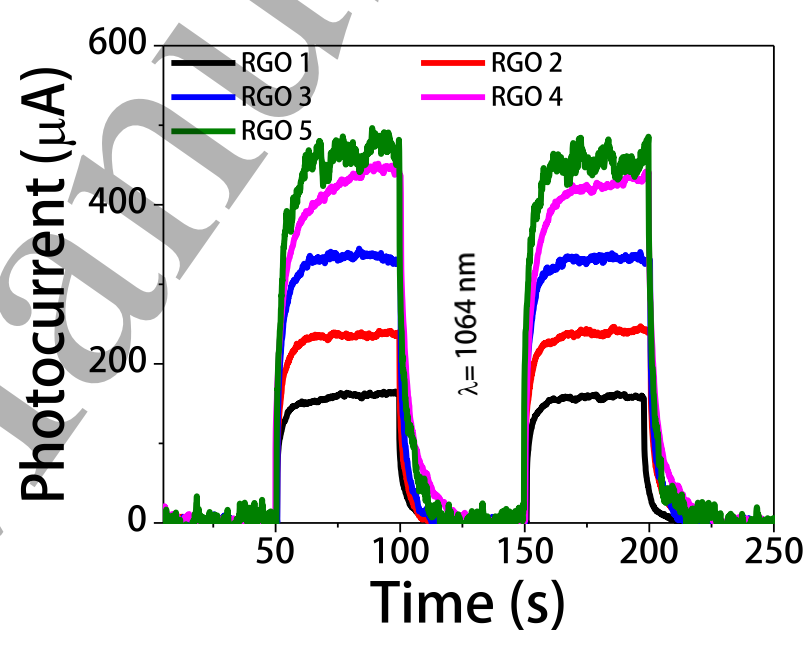

(d)

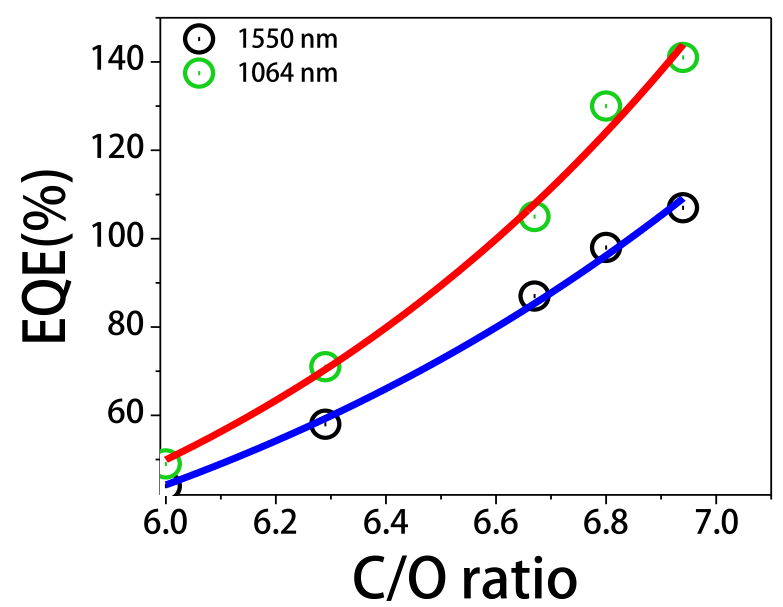

Figure 3. Temporal response of different RGOs for (a) $1550 \mathrm{~nm}$ and (b) $1064 \mathrm{~nm}$ radiation $\left(\mathrm{I}_{\mathrm{L}}=80( \pm\right.$ $0.6) \mathrm{mW}, \mathrm{cm}^{-2}$ and $\left.\mathrm{V}_{\mathrm{S}-\mathrm{D}}=0.5 \mathrm{~V}\right)$. (c) Photocurrent and (d) EQE vs. C/O ratio of RGOs $\left(\mathrm{I}_{\mathrm{L}}=80( \pm 0.6)\right.$ $\mathrm{mW} \cdot \mathrm{cm}^{-2}$ and $\left.\mathrm{V}_{\mathrm{S}-\mathrm{D}}=0.5 \mathrm{~V}\right)$. 
Table 2. Responsivity and EQE of RGOs at $\mathrm{I}_{\mathrm{L}}=80( \pm 0.6) \mathrm{mW} \cdot \mathrm{cm}^{-2}$ and $\mathrm{V}_{\mathrm{S}-\mathrm{D}}=0.5 \mathrm{~V}$.

\begin{tabular}{|c|c|c|c|c|}
\hline Sample & \multicolumn{2}{|c|}{ R (A/W) } & \multicolumn{2}{c|}{ EQE(\%) } \\
& $\lambda(1550 \mathrm{~nm})$ & $\lambda(1064 \mathrm{~nm})$ & $\lambda(1550 \mathrm{~nm})$ & $\lambda(1064 \mathrm{~nm})$ \\
\hline RGO 1 & 0.55 & 0.42 & 44 & \\
\hline RGO 2 & 0.72 & 0.61 & 58 & 72 \\
\hline RGO 3 & 1.09 & 0.91 & 87 & 106 \\
\hline RGO 4 & 1.23 & 1.11 & 98 & 129 \\
\hline RGO 5 & 1.34 & 1.21 & 107 & 141 \\
\hline
\end{tabular}

Responsivity and EQE values for $1550 \mathrm{~nm}$ and $1064 \mathrm{~nm}$ excitation are listed in table 2. Variation of EQE values with the C/O ratio in RGO for both $1064 \mathrm{~nm}$ and $1550 \mathrm{~nm}$ infrared irradiation have been shown in figure 3(d). Data points are well fitted with the equation,

$\boldsymbol{E Q E}=\boldsymbol{\kappa} * \boldsymbol{x}^{\gamma}$

where $\boldsymbol{x}=\mathrm{C} / \mathrm{O}$ ratio and $\boldsymbol{\kappa}$ and $\boldsymbol{\gamma}$ are constants. $\boldsymbol{\gamma}$ for 1550 and $1064 \mathrm{~nm}$ radiation is $\sim 6.2$ and 7.2, respectively indicates faster increase of EQE for $1064 \mathrm{~nm}$ excitation as compared to 1550 nm.

I-V characteristic shows Coulomb blockade effect specially at low temperature (Figure S9 a). Transport of charge carriers through RGO sheets occurs via hopping mechanism (Figure S9 b). As discussed earlier, the band gap decreases with increase of $\mathrm{C} / \mathrm{O}$ ratio that leads to increase of photocurrent as well as the EQE. Higher absorption at $1064 \mathrm{~nm}$ is believed to be the underlying reason for higher $\gamma$ value for $1064 \mathrm{~nm}$ radiation as compared to $1550 \mathrm{~nm}$. In this context, the role 
of mid-gap state band (MGB) needs to be discussed. Although RGOs are highly reduced, still they contain $\sim 14.3 \%$ to $12.6 \%$ oxygen (atomic percentage). The reduction of sheet size, incorporation of defects during sonication, high temperature reduction and presence of oxygen functionalities are believed to create MGB in RGOs.[6, 45-47] MGB can trap photoexcited electrons.[6, 48] During the lifetime of trapped electrons corresponding holes recirculate trough the circuit generating a gain in photocurrent (Schematic 1).[6, 48-53] Thus, combined effects of higher absorption and presence of MGB in RGO lead to high responsivity and EQE values of our RGO based photodetectors.EQE exceeds $100 \%$ for both 1550 and $1064 \mathrm{~nm}$ irradiation for highly reduced graphene oxide based devices.

Schematic 1: Electron trapping in mid-gap state and hole hopping. 
temperature increases, trapping becomes less effective that leads to lower photocurrent. Plot of photocurrent vs. temperature indicates almost linear variation of photocurrent with temperature (Figure 4b). Thus the prepared RGO shows potential as a temperature sensor.

(a)

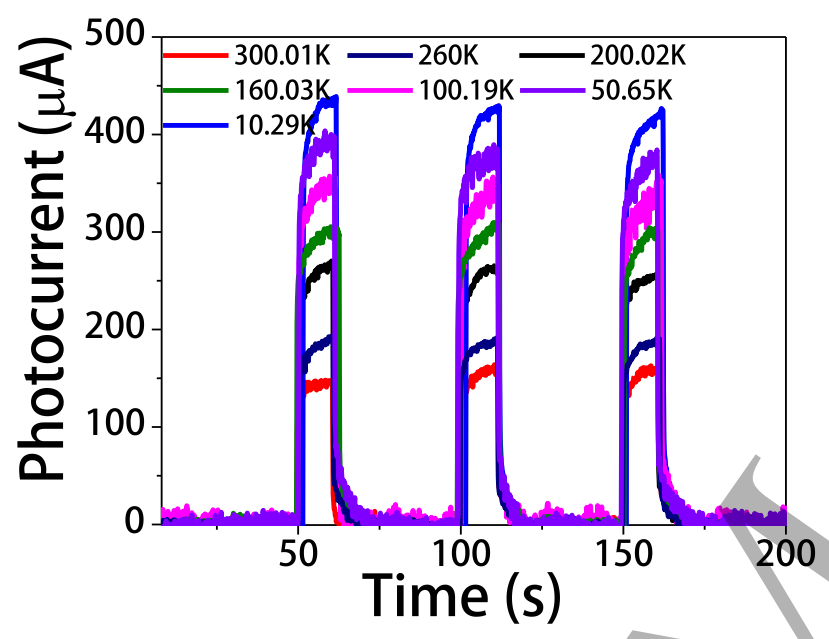

(b)

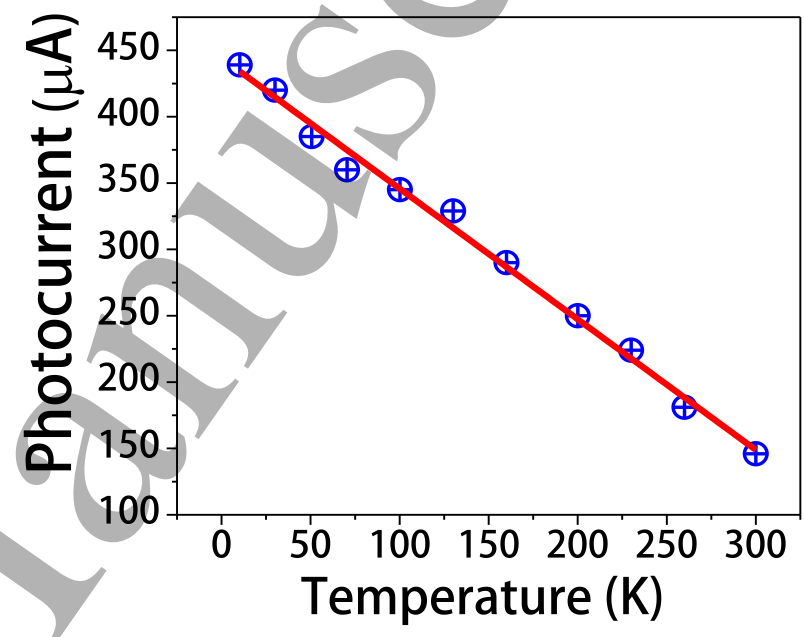

Figure 4. (a) Temporal photoresponse of RGO 4 at different temperature $(\lambda=632 \mathrm{~nm})$, (b) Variation of photocurrent with temperature.

In most cases, the responsivity of graphene or RGO is in range of few $\mathrm{mA} . \mathrm{W}^{-1}$ or less.[13, 14 , 42, 54-62] Due to poor absorption and fast carrier recombination, EQE is very low for monolayer or very few layer graphene based photodetector. The responsivity and EQE values of our RGOs are comparable with the graphene nano-ribbon as an active material.[44] Using RGO or graphene as the only active material, the responsivity of prepared RGO is found to be better than many of the reported literature.

Both rise (figure 5a) and decay (figure 5b) of photocurrent are fitted with the following exponential relation, 
$I_{t}=I_{f}+A_{1} * \exp \left(-t / \tau_{1}\right)+A_{2} * \exp \left(-t / \tau_{2}\right)$,

where $\boldsymbol{I}_{\boldsymbol{t}}$ is photocurrent at any time $\mathbf{t}$ and $\boldsymbol{I}_{\boldsymbol{f}}$ is the final photocurrent, $\boldsymbol{A}_{\boldsymbol{I}}$ and $\boldsymbol{A}_{\boldsymbol{2}}$ are constants (depends on incident light intensity), and $\tau_{1}$ and $\tau_{2}$ are time constants.[7, 44, 48] Rise and decay of photocurrent for $1064 \mathrm{~nm}$ excitation have been shown in figure S10 (a) and (b). Values of time constants are evaluated for RGOs and provided in table 3 (1550 nm excitation) and table S2 (1064 $\mathrm{nm}$ excitation). All the cases, $\tau$ values indicate a faster growth (or decay) followed by a slower saturation. These results are in accordance with the previous reports.[7, 44] The values of time constants indicate that the responses of our RGO based photodetectors are faster than many other reported values.

(a)

(b)
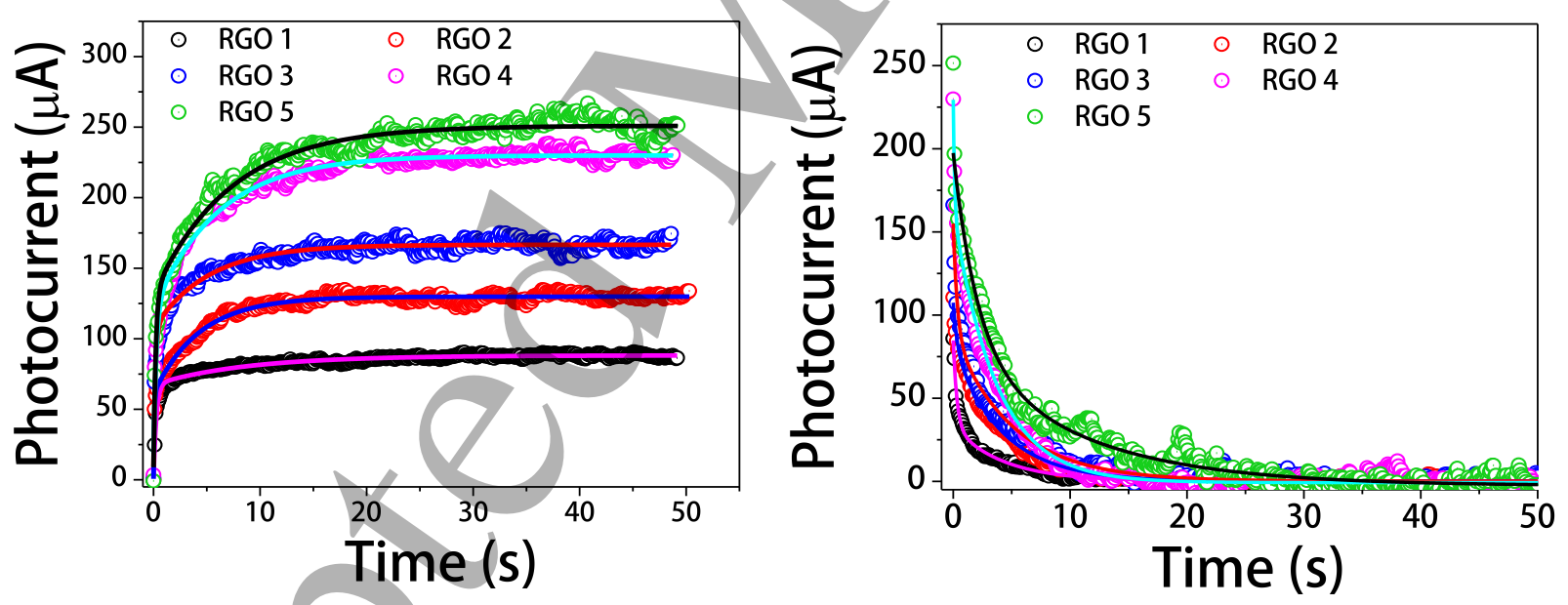

Figure 5. (a) Rise and (b) decay of photocurrent (1550 nm excitation) of different RGOs $\left(\mathrm{V}_{\mathrm{S}-\mathrm{D}}=0.3 \mathrm{~V}\right.$, $\left.\mathrm{I}_{\mathrm{L}}=80( \pm 0.6) \mathrm{mW} \cdot \mathrm{cm}^{-2}\right)$.

Reproducibility of photocurrent is checked over 20 cycles (Figure S11). A brief summary of results from previous works on graphene and RGO based photodetector have been listed in table 


\section{CONCLUSIONS}

Table 3. Time constants, response and recovery time of photodetectors for $1550 \mathrm{~nm}$ infrared irradiation $\left(\mathrm{V}_{\mathrm{S}-\mathrm{D}}=0.3 \mathrm{~V}, \mathrm{I}_{\mathrm{L}}=80( \pm 0.6) \mathrm{mW} \cdot \mathrm{cm}^{-2}\right)$.

\begin{tabular}{|c|c|c|c|c|}
\hline Active & \multicolumn{3}{|c|}{ Rise(s) } & \multicolumn{2}{c|}{ Decay (s) } \\
Material & \multicolumn{2}{|c|}{$\tau_{1}$} & $\tau_{2}$ & \multicolumn{2}{c|}{$\tau_{1}$} \\
\hline RGO 1 & 0.25 & 8.78 & 0.32 & 4.27 \\
\hline RGO 2 & 0.07 & 4.30 & 0.34 & 4.22 \\
\hline RGO 3 & 0.17 & 5.12 & 0.35 & 5.19 \\
\hline RGO 4 & 0.25 & 6.10 & 0.12 & 3.66 \\
\hline RGO 5 & 0.20 & 7.20 & 2.03 & 10.49 \\
\hline
\end{tabular}

We have prepared highly reduced RGO by solvothermal reduction in ethanol. Devices have been fabricated by drop casting RGO on silver electrodes. Infrared photoresponse studies of the devices have been carried out with 1550 and $1064 \mathrm{~nm}$ laser source and the photocurrent is found to be photovoltaic in nature. Interestingly, EQE increases with $\mathrm{C} / \mathrm{O}$ ratio and higher than $100 \%$ is obtained for RGO with higher $\mathrm{C} / \mathrm{O}$ ratio which is believed to be due to the combined effects of strong absorption and mid-gap states assisted gain. Highest responsivity obtained in our experiment is 1.34 and 1.21 for $1550 \mathrm{~nm}$ and $1064 \mathrm{~nm}$ infrared irradiation, respectively. The responsivity and response time of our photodetectors is much better than many of those values which are already reported for RGO based photodetector and comparable with commercial ones. 
In addition, our RGO based photodetectors exhibit stable and reproducible photocurrent over many cycles. Another interesting observation is that the photocurrent decreases almost linearly with temperature which can be exploited as temperature sensor as well.

Conflicts of Interest: The authors declare that they have no conflict of interest.

\section{REFERENCES}

[1] Rogalski, A. 2009 Infrared detectors for the future. Acta Physica Polonica-Series A General Physics, 116 (3), 389.

[2] Nair, R.; Blake, P.; Grigorenko, A.; Novoselov, K.; Booth, T.; Stauber, T.; Peres, N.; Geim, A. 2008 Fine structure constant defines visual transparency of graphene. Science, 320 (5881), 1308-1308.

[3] Breusing, M.; Ropers, C.; Elsaesser, T. 2009 Ultrafast carrier dynamics in graphite. Physical review letters, 102 (8), 086809.

[4] George, P. A.; Strait, J.; Dawlaty, J.; Shivaraman, S.; Chandrashekhar, M.; Rana, F.; Spencer, M. G. 2008 Ultrafast Optical-Pump Terahertz-Probe Spectroscopy of the Carrier Relaxation and Recombination Dynamics in Epitaxial Graphene. Nano Letters, 8 (12), 4248-4251.

[5] Rana, F.; George, P. A.; Strait, J. H.; Dawlaty, J.; Shivaraman, S.; Chandrashekhar, M.; Spencer, M. G. 2009 Carrier recombination and generation rates for intravalley and intervalley phonon scattering in graphene. Physical Review B, 79 (11), 115447.

[6] Zhang, B. Y.; Liu, T.; Meng, B.; Li, X.; Liang, G.; Hu, X.; Wang, Q. J. 2013 Broadband high photoresponse from pure monolayer graphene photodetector. Nat Commun, 4, 1811.

[7] Chang, H.; Sun, Z.; Saito, M.; Yuan, Q.; Zhang, H.; Li, J.; Wang, Z.; Fujita, T.; Ding, F.; Zheng, Z.; Yan, F.; Wu, H.; Chen, M.; Ikuhara, Y. 2013 Regulating Infrared Photoresponses in Reduced Graphene Oxide Phototransistors by Defect and Atomic Structure Control. ACS Nano, 7 (7), 6310-6320.

[8] Gowda, P.; Mohapatra, D. R.; Misra, A. 2015 Photoresponse of double-stacked graphene to Infrared radiation. Nanoscale, 7 (38), 15806-15813.

[9] Lu, S.; Panchapakesan, B. 2006 Photoconductivity in single wall carbon nanotube sheets. Nanotechnology, 17 (8), 1843.

[10] Gowda, P.; Sakorikar, T.; Reddy, S. K.; Ferry, D. B.; Misra, A. 2014 Defect-Induced Enhancement and Quenching Control of Photocurrent in Few-Layer Graphene Photodetectors. ACS Applied Materials \& Interfaces, 6 (10), 7485-7490.

[11] Liu, Y.; Cheng, R.; Liao, L.; Zhou, H.; Bai, J.; Liu, G.; Liu, L.; Huang, Y.; Duan, X. 2011 Plasmon resonance enhanced multicolour photodetection by graphene. Nat Commun, 2, 579.

[12] Echtermeyer, T. J.; Britnell, L.; Jasnos, P. K.; Lombardo, A.; Gorbachev, R. V.; Grigorenko, A. N.; Geim, A. K.; Ferrari, A. C.; Novoselov, K. S. 2011 Strong plasmonic enhancement of photovoltage in graphene. Nat Commun, 2, 458.

[13] Zhu, J.; Liu, Q. H.; Lin, T. 2013 Manipulating light absorption of graphene using plasmonic nanoparticles. Nanoscale, 5 (17), 7785-7789. 
[14] Furchi, M.; Urich, A.; Pospischil, A.; Lilley, G.; Unterrainer, K.; Detz, H.; Klang, P.; Andrews, A. M.; Schrenk, W.; Strasser, G.; Mueller, T. 2012 Microcavity-Integrated Graphene Photodetector. Nano Letters, 12 (6), 2773-2777.

[15] Bae, S.; Kim, H.; Lee, Y.; Xu, X.; Park, J.-S.; Zheng, Y.; Balakrishnan, J.; Lei, T.; Ri Kim, H.; Song, Y. I.; Kim, Y.-J.; Kim, K. S.; Ozyilmaz, B.; Ahn, J.-H.; Hong, B. H.; lijima, S. 2010 Roll-to-roll production of 30-inch graphene films for transparent electrodes. Nat Nano, 5 (8), 574-578.

[16] Loomis, J.; Panchapakesan, B.2012 Large photocurrents in single layer graphene thin films: effects of diffusion and drift. Nanotechnology, 23 (26), 265203.

[17] Yang, H.; Cao, Y.; He, J.; Zhang, Y.; Jin, B.; Sun, J.-L.; Wang, Y.; Zhao, Z. 2017 Highly conductive free-standing reduced graphene oxide thin films for fast photoelectric devices. Carbon 115, 561-570.

[18] Gómez-Navarro, C.; Weitz, R. T.; Bittner, A. M.; Scolari, M.; Mews, A.; Burghard, M.; Kern, K. 2007 Electronic Transport Properties of Individual Chemically Reduced Graphene Oxide Sheets. Nano Letters, 7(11),3499-3503.

[19] Wei, Z.; Wang, D.; Kim, S.; Kim, S.-Y.; Hu, Y.; Yakes, M. K.; Laracuente, A. R.; Dai, Z.; Marder, S. R.; Berger, C.; King, W. P.; de Heer, W. A.; Sheehan, P. E.; Riedo, E. 2010 Nanoscale Tunable Reduction of Graphene Oxide for Graphene Electronics. Science, 328(5984), 1373-1376.

[20] Eda, G.; Fanchini, G.; Chhowalla, M. 2008 Large-area ultrathin films of reduced graphene oxide as a transparent and flexible electronic material. Nature nanotechnology, 3 (5), 270-274.

[21] Mathkar, A.; Tozier, D.; Cox, P.; Ong, P.; Galande, C.; Balakrishnan, K.; Leela Mohana Reddy, A.; Ajayan, P. M. 2012 Controlled, stepwise reduction and band gap manipulation of graphene oxide. The Journal of Physical Chemistry Letters, 3 (8), 986-991.

[22] Tang, Q.; Zhou, Z.; Chen, Z. 2013 Graphene-related nanomaterials: tuning properties by functionalization. Nanoscale, 5 (11), 4541-4583.

[23] Stankovich, S.; Dikin, D. A.; Piner, R. D.; Kohlhaas, K. A.; Kleinhammes, A.; Jia, Y.; Wu, Y.; Nguyen, S. T.; Ruoff, R. S. 2007 Synthesis of graphene-based nanosheets via chemical reduction of exfoliated graphite oxide. Carbon, 45 (7), 1558-1565.

[24] Zhang, J.; Yang, H.; Shen, G.; Cheng, P.; Zhang, J.; Guo, S. 2010 Reduction of graphene oxide via L-ascorbic acid. Chemical Communications, 46 (7), 1112-1114.

[25] Pham, V. H.; Pham, H. D.; Dang, T. T.; Hur, S. H.; Kim, E. J.; Kong, B. S.; Kim, S.; Chung, J. S. 2012 Chemical reduction of an aqueous suspension of graphene oxide by nascent hydrogen. Journal of Materials Chemistry, 22 (21), 10530-10536.

[26] Barman, B. K.; Nanda, K. K. 2015 Si-mediated fabrication of reduced graphene oxide and its hybrids for electrode materials. Green Chemistry, 17 (2), 776-780.

[27] Dreyer, D. R.; Murali, S.; Zhu, Y.; Ruoff, R. S.; Bielawski, C. W. 2011 Reduction of graphite oxide using alcohols. Journal of Materials Chemistry, 21 (10), 3443-3447.

[28] Hummers Jr, W. S.; Offeman, R. E. 1958 Preparation of graphitic oxide. Journal of the American Chemical Society, 80 (6), 1339-1339.

[29] Park, S.; An, J.; Potts, J. R.; Velamakanni, A.; Murali, S.; Ruoff, R. S. 2011 Hydrazine-reduction of graphite-and graphene oxide. Carbon, 49 (9), 3019-3023.

[30] Some, S.; Kim, Y.; Hwang, E.; Yoo, H.; Lee, H. 2012 Binol salt as a completely removable graphene surfactant. Chemical Communications, 48 (62), 7732-7734.

[31] Ferrari, A. C. 2007 Raman spectroscopy of graphene and graphite: disorder, electron-phonon coupling, doping and nonadiabatic effects. Solid state communications, 143 (1), 47-57.

[32] Wang, Y.; Alsmeyer, D. C.; McCreery, R. L. 1990 Raman spectroscopy of carbon materials: structural basis of observed spectra. Chemistry of Materials, 2 (5), 557-563.

[33] Tuinstra, F.; Koenig, J. L. 1970 Raman spectrum of graphite. The Journal of Chemical Physics, 53 (3), 1126-1130. 
[34] Ferrari, A. C.; Robertson, J. 2000 Interpretation of Raman spectra of disordered and amorphous carbon. Physical review B, 61 (20), 14095.

[35] Pimenta, M.; Dresselhaus, G.; Dresselhaus, M. S.; Cancado, L.; Jorio, A.; Saito, R. 2007 Studying disorder in graphite-based systems by Raman spectroscopy. Physical chemistry chemical physics, 9 (11), 1276-1290.

[36] Kind, H.; Yan, H.; Messer, B.; Law, M.; Yang, P. 2002 Nanowire ultraviolet photodetectors and optical switches. Advanced materials, 14 (2), 158.

[37] Rose, A. 1978Concepts in photoconductivity and allied problems. Krieger: Huntington, N.Y.

[38] Bae, J. J.; Yoon, J. H.; Jeong, S.; Moon, B. H.; Han, J. T.; Jeong, H. J.; Lee, G.-W.; Hwang, H. R.; Lee, Y. H.; Jeong, S. Y. 2015 Sensitive photo-thermal response of graphene oxide for mid-infrared detection. Nanoscale, 7 (38), 15695-15700.

[39] Liang, H. 2014 Mid-infrared response of reduced graphene oxide and its high-temperature coefficient of resistance. AIP Advances, 4 (10), 107131.

[40] Jeong, H.; Jin, M.; So, K.; Lim, S.; Lee, Y. 2009 Tailoring the characteristics of graphite oxides by different oxidation times. Journal of Physics D: Applied Physics, 42 (6), 065418.

[41] Kumar, P. V.; Bernardi, M.; Grossman, J. C. 2013 The impact of functionalization on the stability, work function, and photoluminescence of reduced graphene oxide. ACS nano, 7 (2), 1638-1645.

[42] Xia, F.; Mueller, T.; Lin, Y.-m.; Valdes-Garcia, A.; Avouris, P. 2009 Ultrafast graphene photodetector. Nature nanotechnology, 4 (12), 839-843.

[43] An, X.; Liu, F.; Jung, Y. J.; Kar, S. 2013 Tunable graphene-silicon heterojunctions for ultrasensitive photodetection. Nano letters, 13 (3), 909-916.

[44] Chitara, B.; Panchakarla, L.; Krupanidhi, S. B.; Rao, C. N. R. 2011 Infrared photodetectors based on reduced graphene oxide and graphene nanoribbons. Advanced Materials, 23 (45), 5419-5424.

[45] Wehling, T.; Katsnelson, M.; Lichtenstein, A. 2009 Impurities on graphene: Midgap states and migration barriers. Physical Review B, 80 (8), 085428.

[46] Stauber, T.; Peres, N.; Guinea, F. 2007 Electronic transport in graphene: A semiclassical approach including midgap states. Physical Review B, 76 (20), 205423.

[47] Chen, J.-H.; Cullen, W.; Jang, C.; Fuhrer, M.; Williams, E. 2009 Defect scattering in graphene. Physical review letters, 102 (23), 236805.

[48] Ito, Y.; Zhang, W.; Li, J.; Chang, H.; Liu, P.; Fujita, T.; Tan, Y.; Yan, F.; Chen, M. 2016 3D Bicontinuous Nanoporous Reduced Graphene Oxide for Highly Sensitive Photodetectors. Advanced Functional Materials, 26 (8), 1271-1277.

[49] Chen, R.-S.; Chen, H.-Y.; Lu, C.-Y.; Chen, K.-H.; Chen, C.-P.; Chen, L.-C.; Yang, Y.-J. 2007 Ultrahigh photocurrent gain in m-axial GaN nanowires. Applied Physics Letters, 91 (22), 223106.

[50] Li, L.; Zhang, F.; Wang, J.; An, Q.; Sun, Q.; Wang, W.; Zhang, J.; Teng, F. 2015 Achieving EQE of $16,700 \%$ in P3HT: PC71BM based photodetectors by trap-assisted photomultiplication. Scientific reports, 5(9181), 1-7.

[51] Li, L.; Zhang, F.; Wang, W.; An, Q.; Wang, J.; Sun, Q.; Zhang, M. 2015 Trap-Assisted Photomultiplication Polymer Photodetectors Obtaining an External Quantum Efficiency of 37500\%. ACS Applied Materials \& Interfaces, 7 (10), 5890-5897.

[52] Li, X.; Wang, S.; Xiao, Y.; Li, X. 2016 A trap-assisted ultrasensitive near-infrared organic photomultiple photodetector based on Y-type titanylphthalocyanine nanoparticles. Journal of Materials Chemistry C, 4 (24), 5584-5592.

[53] Bhattacharya, P. 1997 Semiconductor Optoelectronic Devices. Chap. 8, 346-351.

[54] Gabor, N. M.; Song, J. C.; Ma, Q.; Nair, N. L.; Taychatanapat, T.; Watanabe, K.; Taniguchi, T.; Levitov, L. S.; Jarillo-Herrero, P. 2011 Hot carrier-assisted intrinsic photoresponse in graphene. Science, 334 (6056), 648-652. 
[55] Fernandes, G. E.; Kim, J. H.; Oller, D.; Xu, J. 2015 Reduced graphene oxide mid-infrared photodetector at $300 \mathrm{~K}$. Applied Physics Letters, 107 (11), 111111.

[56] Freitag, M.; Low, T.; Avouris, P. 2013 Increased responsivity of suspended graphene photodetectors. Nano letters, 13 (4), 1644-1648.

[57] Pospischil, A.; Humer, M.; Furchi, M. M.; Bachmann, D.; Guider, R.; Fromherz, T.; Mueller, T. 2013 CMOS-compatible graphene photodetector covering all optical communication bands. Nature Photonics, 7 (11), 892-896.

[58] Gan, X.; Shiue, R.-J.; Gao, Y.; Meric, I.; Heinz, T. F.; Shepard, K.; Hone, J.; Assefa, S.; Englund, D. 2013 Chip-integrated ultrafast graphene photodetector with high responsivity. Nature Photonics, 7 (11), 883-887.

[59] Xia, F.; Mueller, T.; Golizadeh-Mojarad, R.; Freitag, M.; Lin, Y.-m.; Tsang, J.; Perebeinos, V.; Avouris, P. 2009 Photocurrent imaging and efficient photon detection in a graphene transistor. Nano letters, 9 (3), 1039-1044.

[60] Mueller, T.; Xia, F.; Avouris, P. 2010 Graphene photodetectors for high-speed optical communications. Nature Photonics, 4 (5), 297-301.

[61] Radoi, A.; Iordanescu, A.; Cismaru, A.; Dragoman, M.; Dragoman, D. 2010 Ultrabroadband photodetection based on graphene ink. Nanotechnology, 21 (45), 455202.

[62] Chowdhury, F. A.; Mochida, T.; Otsuki, J.; Alam, M. S. 2014 Thermally reduced solutionprocessed graphene oxide thin film: An efficient infrared photodetector. Chemical Physics Letters, 593, 198-203. 